\title{
Development and optimized pairing of mouse monoclonal antibodies for detecting hemagglutinin in novel $\mathrm{H} 7$ subtype influenza viruses
}

\author{
Huijuan Wang, Jianfang Zhou, Dayan Wang, Baoying Huang ${ }^{*} \&$ Wenjie Tan ${ }^{*}$ \\ NHC Key Laboratory of Biosafety, National Institute for Viral Disease Control \& Prevention, Chinese Center for Disease Control and \\ Prevention, China CDC, Beijing 102206, China
}

Received December 12, 2018; accepted January 23, 2019; published online May 28, 2019

\begin{abstract}
The H7 subtype avian influenza threatens public health with respect to poultry and humans. Thus, a specific and sensitive diagnostic test is essential for the management of $\mathrm{H} 7$ subtype influenza infections. In this study, five mouse monoclonal antibodies (mAbs) against hemagglutinin (HA) of influenza A/Anhui/1/2013 (H7N9) were produced and characterized by the Western blot, immunofluorescence, and hemagglutination inhibition assays. All five specific mAbs reacted with the HA protein of $\mathrm{H} 7 \mathrm{~N} 9$ but not with that of H1N1, H3N2, or H5N1. With the combination arrays of capture and detection antibodies, the matched pair mAbs (1C4-coated and 2D7-labeled) were selected and employed in a double-antibody sandwich ELISA (DASELISA). Detection limits of the sandwich ELISA were $0.45 \mathrm{ng} \mathrm{mL}^{-1}$ for the HA protein derived from A/Anhui/1/2013 (H7N9); or 1 and $2 \mathrm{HA}$ units/50 $\mu \mathrm{L}$ for A/Anhui/1/2013 (H7N9) and A/GD/17SF003/2016 (H7N9), respectively. These anti-HA mAbs against subtype $\mathrm{H} 7$ and the novel DAS-ELISA provide a valuable approach for specific detection of the H7 subtype influenza virus and quantification of its HA protein, especially for the novel epidemic H7N9.
\end{abstract}

influenza A, H7 subtype, hemagglutinin, monoclonal antibodies, sandwich ELISA

Citation: Wang, H., Zhou, J., Wang, D., Huang, B., and Tan, W. (2020). Development and optimized pairing of mouse monoclonal antibodies for detecting hemagglutinin in novel H7 subtype influenza viruses. Sci China Life Sci 63, 279-289. https://doi.org/10.1007/s11427-018-9486-0

\section{INTRODUCTION}

A novel reassortant avian influenza H7N9 virus infecting humans was first reported in March 2013 (Gao et al., 2013). As of June 17, 2018, the Food and Agriculture Organization of the United Nations has reported 1,625 human cases with 623 deaths (http://www.fao.org/ag/againfo/programmes/en/ empres/H7N9/situation_update.html). Although no sustained transmission was observed within humans, the influenza A (H7N9) virus has caused five epidemics and has evolved and clustered into two diversified lineages based on the hemagglutinin (HA) genes: the Yangtze River Delta

*Corresponding authors (Baoying Huang, email: baoying1233@163.com; Wenjie Tan, email: tanwj28@163.com) lineage and the Pearl River Delta lineage (Wang et al., 2016; Qi et al, 2018). Notably, before 2016, the low pathogenic avian influenza (LPAI) H7N9 was circulated with little disease in the infected poultry; however, it could cause severe infections in humans. With the evolution of these viruses, highly pathogenic avian influenza (HPAI) H7N9, in which multiple basic amino acids (aa) are inserted into the cleavage site of the HA protein, reportedly infected humans in the fifth epidemic (2016-2017) (Yang et al., 2017). The HPAI H7N9 viruses were also detected in poultry markets and caused several severe disease outbreaks in chicken farms (http:// www.oie.int/wahis_2/public/wahid.php/Reviewreport/Review?reportid=23367). As of November 7, 2018, the HPAI $\mathrm{H} 7 \mathrm{~N} 9$ viruses have been reported in birds or environments in at least 14 provinces, municipalities, or autonomous regions 
in China (http://www.fao.org/ag/againfo/programmes/en/ empres/H7N9/situation_update.html). Importantly, the H7N9 virus could acquire additional mutations during their replication in ferrets or humans and could become highly lethal in mammals and transmissible in ferrets by respiratory droplet (Yang et al., 2017; Shi et al., 2017; Qi et al, 2018; Shi et al., 2018). An extended geographic spread of the virus was also observed in poultry markets and farms in early 2017 (Quan et al., 2018; Shi et al., 2018). The H7N9 viruses currently co-circulate with influenza H1N1 and H3N2 and are reassorted with other unknown influenza viruses ( $\mathrm{Li}$ et al., 2014; Shi et al., 2018; Zeng et al., 2018), exhibiting an increased replicative ability and medium-to-high pathogenicity in ducks (Shi et al., 2018; Zeng et al., 2018). Thus, the circulation of $\mathrm{H} 7$ subtype avian influenza poses a potential pandemic threat for both poultry and humans.

The rapid detection of $\mathrm{H} 7$ subtype avian influenza is essential for early treatment and effective management. The currently available detection methods for $\mathrm{H} 7$ subtype influenza $A$ (such as H7N9) recommended by the World Health Organization (WHO) include virus isolation and nucleoidbased quantitative reverse transcription PCR (qRT-PCR) (WHO Global Influenza Surveillance Network, 2011), which usually require BSL-3 containment and are time-consuming. By contrast, the antigen detection methods based on enzymelinked immunosorbent assay (ELISA) have repeatedly shown their value in the diagnosis of influenza infection (Koski and Klepser, 2017). Double-antibody sandwich ELISA (DAS-ELISA) with matched antibody pairs is typically more sensitive than direct or indirect ELISA. As capture and detection antibodies usually target a nonoverlapping region of the antigen, DAS-ELISA also delivers high specificity (Shah and Maghsoudlou, 2016).

However, the most currently available influenza antigen detection methods are targeted toward the viral nucleoprotein, which is conserved in all influenza subtype A viruses and is therefore non-specific to subtype H7 influenza. HA is a major membrane protein of influenza viruses, forming spikes on the surface of the virus to mediate viral attachment and entry. The monoclonal antibodies (mAbs) specific to HA protein have potential utility in the detection of subtype $\mathrm{H} 7$ influenza virus, including the current epidemic H7N9.

In this study, we produced and characterized five mouse $m A b s$ against the HA derived from the novel avian influenza A/Anhui/1/2013 (H7N9). We further developed a DASELISA for the detection of $\mathrm{H} 7$ subtype influenza A (including H7N9) with the optimized pairing of these mAbs.

\section{RESULTS}

\section{Generation of mAbs to influenza A (H7N9) HA}

To facilitate the specific antigen detection of $\mathrm{H} 7$ subtype influenza A (including H7N9) and to develop the reagents for the quantity evaluation of candidate vaccines based on the HA derived from novel avian influenza, we developed a panel of mAbs to A/Anhui/1/2013 (H7N9). HA was used on a BALB/c mouse model by utilizing a conventional hybridoma method. One week after the last booster, mouse serum was collected, and the IgG titer was tested by indirect ELISA. The average end-point IgG titer against influenza A/ Anhui/1/2013 (H7N9) HA was measured as 1:51,200 (Figure 1A).

The cell culture supernatants were screened by indirect ELISA with coating by recombinant HA (rHA). The five $\mathrm{mAbs}$ with the strongest binding activity to A/Anhui/1/2013 (H7N9) HA were obtained and designated as 1C4, 2B3, 2D7, $3 \mathrm{E} 4$, and $3 \mathrm{E} 5$. All hybridoma cell lines were found to stably secrete antibodies after sub-culturing for 3 months. Additionally, the isotype determination indicated that all five mAbs were IgG1.

Five $\mathrm{mAbs}$ were generated by inoculating the hybridoma cells into BALB/c mice. Indirect ELISA with coating by rHA was performed to determine the IgG titer in the ascetic fluid. An average $\mathrm{H} 7$ subtype-specific IgG titer of more than 1:512,000 was tested in the ascetic fluid. The end-point IgG titer was $1: 512,000$ for $1 \mathrm{C} 4$ and $3 \mathrm{E} 5$ and more than 1:512,000 for 2B3, 2D7, and 3E4 (Figure 1B).

\section{Characterization of mAbs}

Five mAbs were purified from the ascetic fluid by ammonium sulfate precipitation. The concentration of each purified $\mathrm{mAb}$ was $1 \mu \mathrm{g} \mu \mathrm{L}^{-1}$, as determined by the BCA protein assay. The produced mAbs showed the right molecular weight for each collected $\mathrm{mAb}$, with heavy $(50 \mathrm{kD})$ and light $(25 \mathrm{kD})$ chains indicated by SDS-PAGE analysis (Figure 2A).

To determine the specificity and binding activity of the selected mAbs, we performed Western blot and indirect immunofluorescence assays on the cells transfected with plasmid pVRC8301 or pVRC8301 expressing A/Anhui/1/ 2013 (H7N9), A/GD/17SF003/2016 (H7N9), A/Brisbane/ 10/2007 (H3N2), A/Brisbane/59/2007 (H1N1), and A/PR/8/ 1933 (H1N1) HA. Western blot analysis demonstrated that all five specific mAbs reacted with influenza virus H7N9 HA but none of the HA of the other subtypes of H1N1, H3N2, or $\mathrm{H} 5 \mathrm{~N} 1$; a protein band with $75 \mathrm{kD}$ corresponding to HA0 was observed under reducing conditions (Figure 2B-F), suggesting that these mAbs specifically recognize the linear epitopes on the HA antigen.

Immunofluorescence analysis showed the same results as the Western blot assay. All five specific mAbs reacted with influenza virus H7N9 HA but not the HA of the other subtypes of H1N1, H3N2, or H5N1 (Figure 2G). Altogether, our results indicate that the mAbs $(1 \mathrm{C} 4,2 \mathrm{~B} 3,2 \mathrm{D} 7,3 \mathrm{E} 4$, and 

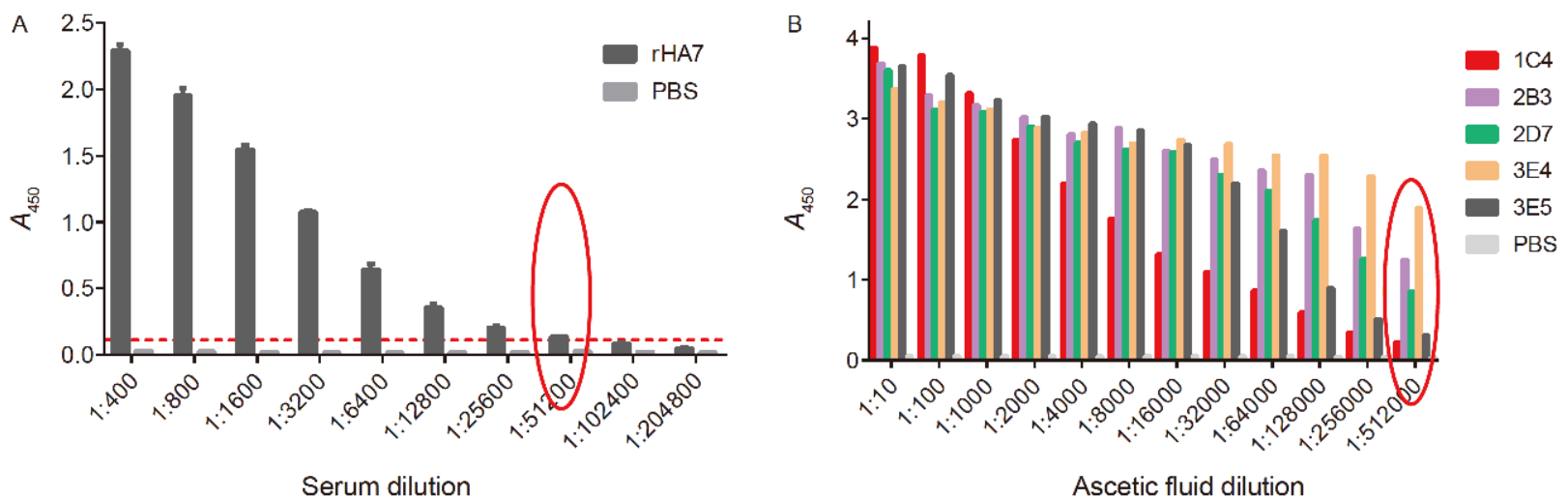

Figure 1 Titration of $\mathrm{H} 7$ subtype-specific antibodies by ELISA. Indirect ELISA using rHA coating was performed to determine the IgG antibody titer against HA. A, Immunized BALB/c mouse serum was collected, and the HA-specific IgG titer against A/Anhui/1/2013 (H7N9) HA was tested by indirect ELISA. The average end-point IgG titer was measured as 1:51,200 in mouse serum. B, HA-specific IgG titer in the murine ascetic fluid. Five hybridoma cell lines with the strongest binding to A/Anhui/1/2013 (H7N9) HA, namely $1 \mathrm{C} 4,2 \mathrm{~B} 3,2 \mathrm{D} 7$, 3E4, and 3E5, were selected. The mAbs were then generated by inoculating the selected hybridoma cells into the BALB/c mice, with an average H7 subtype-specific IgG titer of more than 1:512,000 in the ascetic fluid.

3E5) produced in this study were highly specific to influenza A (H7N9) virus.

The HI test results demonstrated that of the five mAbs, only mAb $1 \mathrm{C} 4$ showed a $\mathrm{HI}$ activity against influenza $\mathrm{A} /$ Anhui/1/2013 H7N9) at a low concentration of $0.025 \mu \mathrm{g} \mathrm{mL}^{-1}$ (Figure 2H).

\section{Epitope mapping of mAbs}

To evaluate the specific regions recognized by the five $\mathrm{mAbs}$, a series of C-terminal truncation HA fragments was constructed into pVRC8301 (Figure 3A) and analyzed by Western blotting assays (Figure 3B). The constructs included the full-length HA (F1, 1-566 aa), HA1 (F2, 1-335 aa), N terminal of HA1 (F3, 1-200 aa) derived from either avian influenza A/Anhui/1/2013 (H7N9), or full-length HA protein of recently epidemic avian influenza A/GD/17SF003/2016 (H7N9) (H7). Western blot analysis demonstrated that the polyclonal mice serum immunized with HA of A/Anhui/1/ 2013 (H7N9) reacted with all the fragments constructed in our study, with $70 \mathrm{kD}$ corresponding to $\mathrm{HA} 0,40 \mathrm{kD}$ corresponding to $\mathrm{HA} 1$, and $25 \mathrm{kD}$ corresponding to the $\mathrm{N}$ terminal of HA1. However, the Western blot assay for all the five mAbs demonstrated notable protein bands of 75 and $40 \mathrm{kD}$ but not $25 \mathrm{kD}$ (Figure 3B) Altogether, our data suggested that these mAbs specifically recognized linear epitopes on the $\mathrm{HA}$ antigen of $\mathrm{H} 7$ subtype influenza at a range of 200-335 aa of HA1.

\section{Optimization of paired mAbs for the development of DAS-ELISA}

To select the matched pair capture/detection antibody for the DAS-ELISA, all the five mAbs $(1 \mathrm{C} 4,2 \mathrm{~B} 3,2 \mathrm{D} 7,3 \mathrm{E} 4$, and $3 E 5)$ were tested in ELISA by paired combination in all possible arrays (Figure 4A-E).
When $1 \mathrm{C} 4$ was used as the capture antibody, combined with $1 \mathrm{C} 4,2 \mathrm{~B} 3,2 \mathrm{D} 7,3 \mathrm{E} 4$, and $3 \mathrm{E} 5$ as the detection antibodies, the detection limits for rHA of subtype $\mathrm{H} 7$ influenza were $62.5,1.8,0.45,0.45$, and $1.8 \mathrm{ng} \mathrm{mL}^{-1}$, respectively (Figure 4F). Meanwhile, 2D7 or 3E4 as the detection antibody resulted in the best sensitivity, with a slightly lower $A$ value for 3E4 (Figure 4A).

When $2 \mathrm{~B} 3$ was used as the capture antibody, combined with $1 \mathrm{C} 4,2 \mathrm{~B} 3,2 \mathrm{D} 7,3 \mathrm{E} 4$, and $3 \mathrm{E} 5$ as the detection antibody, the detection limits for rHA were $3.75,62.5,3.75,7.5$, and $62.5 \mathrm{ng} \mathrm{mL}^{-1}$, respectively (Figure $4 \mathrm{~F}$ ). The $A$ value was much higher and distinct from that of the other mAbs when 1C4 was used as the detection antibody (Figure 4B).

When 2D7 was used as the capture antibody, combined with 1C4, 2B3, 2D7, 3E4, and 3E5 as the detection antibody, the detection limits for rHA were $3.75,125,31,62.5$, and $125 \mathrm{ng} \mathrm{mL}^{-1}$, respectively (Figure $4 \mathrm{~F}$ ). The assay also showed the highest sensitivity when 1C4 was paired as the detection antibody (Figure 4C).

When 3E4 was used as the capture antibody, combined with $1 \mathrm{C} 4,2 \mathrm{~B} 3,2 \mathrm{D} 7,3 \mathrm{E} 4$, and $3 \mathrm{E} 5$ as the detection antibody, the detection limits for rHA were $3.75,62.5,3.75,15$, and $62.5 \mathrm{ng} \mathrm{mL}^{-1}$, respectively (Figure $4 \mathrm{~F}$ ). Using $1 \mathrm{C} 4$ as the detection antibody resulted in the highest sensitivity (Figure 4D).

When 3E5 was used as the capture antibody, combined with $1 \mathrm{C} 4,2 \mathrm{~B} 3,2 \mathrm{D} 7,3 \mathrm{E} 4$, and $3 \mathrm{E} 5$ as the detection antibody, the detection limits for rHA were 3.75, 62.5, 15, 31, and $62.5 \mathrm{ng} \mathrm{mL}^{-1}$, respectively (Figure $4 \mathrm{~F}$ ). The greatest sensitivity was achieved with $1 \mathrm{C} 4$ as the detection antibody (Figure 4E).

Overall, the combination of $1 \mathrm{C} 4$ as the capture antibody and 2D7 as the detection antibody exhibited the best sensitivity and highest $A$ value. Therefore, a novel DAS-ELISA was developed to detect the HA antigen of H7 subtype influenza specifically employing 1C4 to capture the HA and 
A

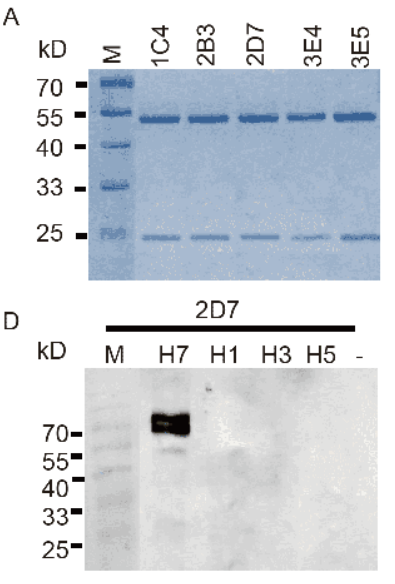

G

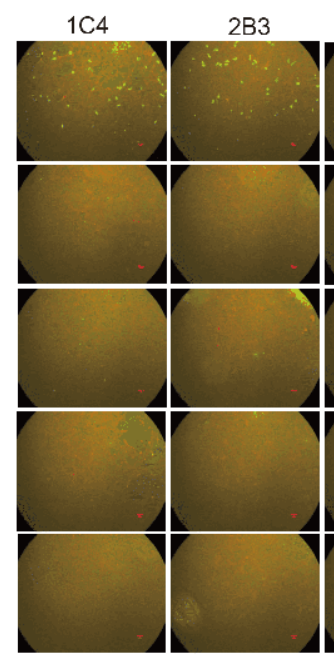

$\mathrm{H}$

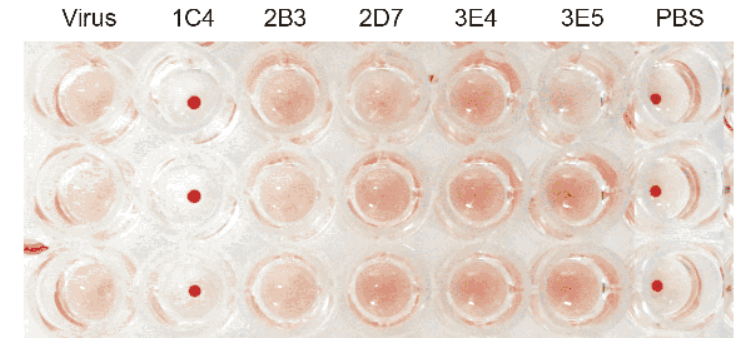

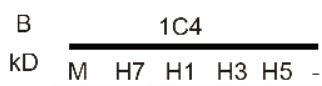

$\begin{array}{llllll}\mathrm{KD} & \mathrm{M} & \mathrm{H} 7 & \mathrm{H} 1 & \mathrm{H} 3 & \mathrm{H} 5\end{array}$

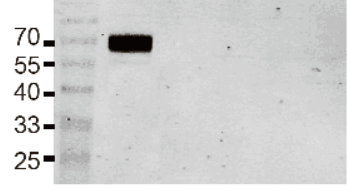

E $\quad 3 \mathrm{E} 4$
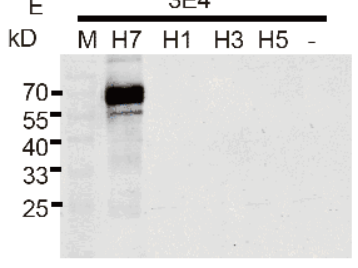

$2 \mathrm{D} 7 \quad 3 \mathrm{E} 4 \quad T^{3 \mathrm{E} 5}$

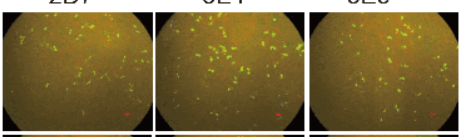

A/Anhui/1/2013(H7N9)

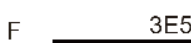

\begin{tabular}{lllll}
\hline $\mathrm{M}$ & $\mathrm{H} 7$ & $\mathrm{H} 1$ & $\mathrm{H} 3$ & $\mathrm{H} 5$
\end{tabular}
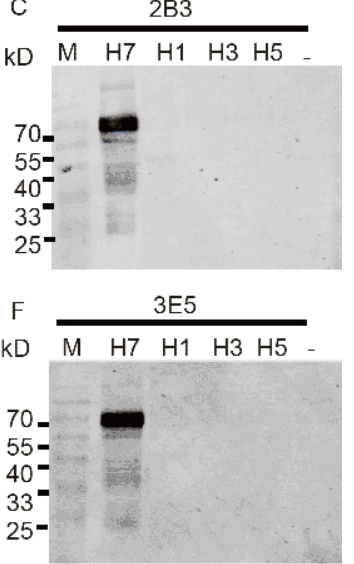

A/Brisbane/59/2007(H1N1)

A/Brisbane/10/2007(H3N2)

A/Anhui/1/2003(H5N1)

pVRC Control

$0.1 \mu \mathrm{g}$

$0.05 \mu \mathrm{g}$

$0.025 \mu \mathrm{g}$

Figure 2 Characterization of the specificity of mAbs against avian influenza H7N9 virus HA. A, Purity analysis of the five mAbs by SDS-PAGE. The two bands indicate the heavy and light chains of individual mAbs after purification. B-G, Specificity of mAbs against HA by Western blot assay (B-F) with 293FT cells or immunofluorescence assay (G), with MDCK cells transfected with pVRC8301 (control) or pVRC8301 expressing A/Anhui/1/2013 (H7N9) HA, A/Anhui/1/2005 (H5N1), A/Brisbane/10/2007 (H3N2), or A/Brisbane/59/2007 (H1N1). H, HI activity of mAbs against avian influenza A/Anhui/1/2013 (H7N9).

horseradish peroxidase (HRP)-conjugated 2D7 for detection.

\section{Specificity and sensitivity of the novel DAS-ELISA}

The specificity and sensitivity of the DAS-ELISA for HA detection of $\mathrm{H} 7$ subtype influenza were further assessed using inactivated influenza A/Anhui/1/2013 (H7N9), A/GD/ 17SF003/2016 (H7N9), A/Brisbane/10/2007 (H3N2), A/ Brisbane/59/2007 (H1N1), and A/PR/8/1933 (H1N1) (Figure $4 \mathrm{~A}$ ). Either the $\mathrm{A} / \mathrm{Anhui} / 1 / 2013$ (H7N9) or $\mathrm{A} / \mathrm{GD} /$ 17SF003/2016 (H7N9) presented positive signals. No cross- reactivity was observed for the other HA subtypes (H1N1 and $\mathrm{H} 3 \mathrm{~N} 2$ ). The sensitivity of the assay was approximately 1 or $2 \mathrm{HA}$ units (HAU) $/ 50 \mu \mathrm{L}$, equal to $62 \mathrm{TCID}_{50} / 50 \mu \mathrm{L}$ and 8 $\mathrm{TCID}_{50} / 50 \mu \mathrm{L}$ for $\mathrm{A} /$ Anhui/1/2013 (H7N9) and $\mathrm{A} / \mathrm{GD} /$ 17SF003/2016 (H7N9), respectively. No cross-reactivity was observed for the other subtypes of influenza viruses. In addition, we performed the experiment with other clinical pathogens in the human respiratory tract, such as human coronaviruses 229E, OC43, NL63, and HKU1, respiratory syncytial virus (RSV), parainfluenza viruses (PIV) 1, 2, and 3 , rhinovirus, and adenovirus (AdV). The results showed that 
A
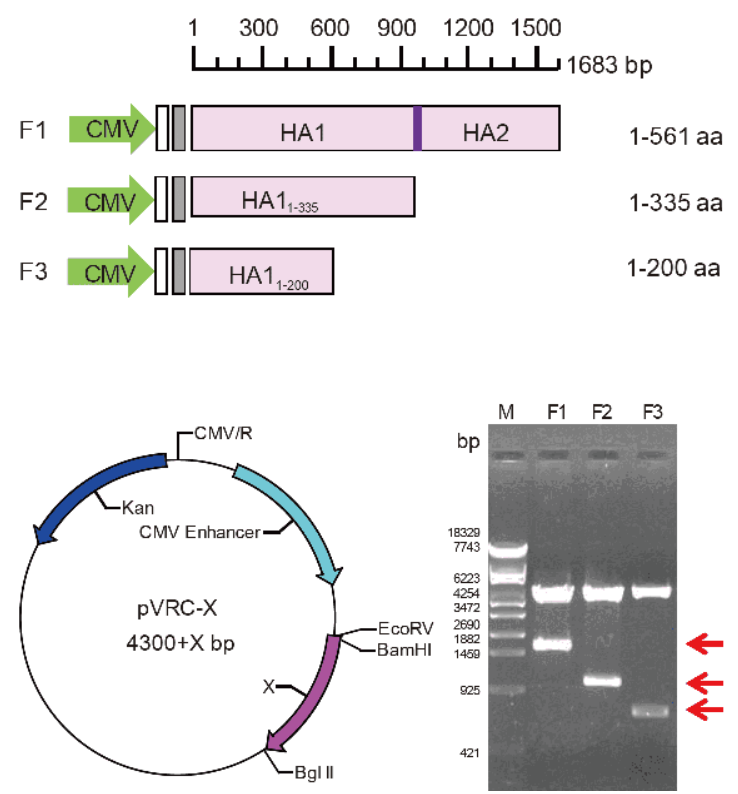

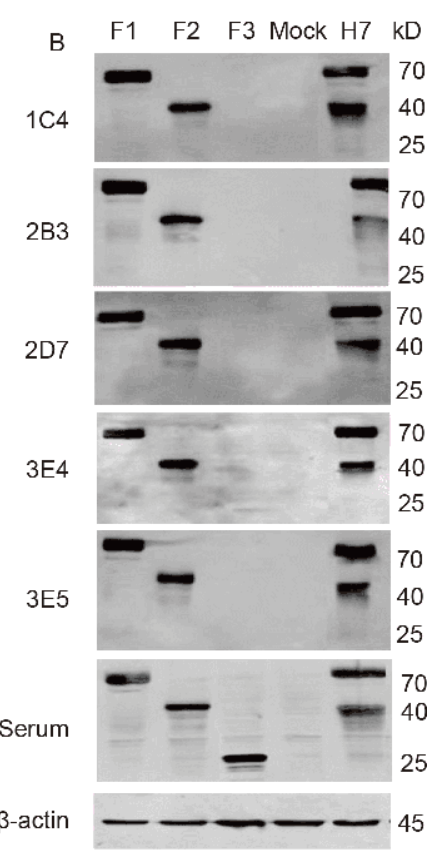

Figure 3 (Color online) Epitope mapping of the mAbs. A, Schematic showing the C-terminal truncation HA fragments of A/Anhui/1/2013(H7N9) in this study and identification by the EcoR V and $B g l$ II enzyme restriction sites. The fragments of the full-length HA, aa 1-335, and aa 1-200 were named as F1, F2, and F3, respectively. B, Western blot assay of 293FT cells transfected with pVRC8301 (mock) or pVRC8301 expressing highly pathogenic avian influenza A/GD/17SF003/2016 (H7N9) HA, which was named as H7 in the results, and fragments of A/Anhui/1/2013(H7N9) HA.

all common pathogens other than $\mathrm{H} 7$ influenza tested negative (data not shown).

To mimic the clinical samples, we also set mimic clinical samples by adding nasal mucosa swab from flu-like illness donors without $\mathrm{H} 7$ influenza virus. Serially diluted inactivated influenza viruses H7N9 were added for the test. Our results showed that the sensitivity for this established DAS-ELISA was estimated to be 1 or $2 \mathrm{HAU} / 50 \mu \mathrm{L}$, corresponding to $62 \mathrm{TCID}_{50} / 50 \mu \mathrm{L}$ and $8 \mathrm{TCID}_{50} / 50 \mu \mathrm{L}$ for A/ Anhui/1/2013 (H7N9) and A/GD/17SF003/2016 (H7N9), respectively, indicating the same level of sensitivity as the results of $\mathrm{H} 7 \mathrm{~N} 9$ virus in PBS.

To further evaluate the detection limitations of this DASELISA, the twofold serially diluted rHA derived from H7 subtype influenza was tested in duplicate. The detection limit of the rHA was approximately $0.0225 \mathrm{ng}$ (Figure 5B). The relationship between the $A_{450}$ and rHA antigen concentration showed a very good linear response in the concentration range from $0.45 \mathrm{ng} \mathrm{mL}^{-1}$ to $500 \mathrm{ng} \mathrm{mL}^{-1}$. The standard curve of the DAS-ELISA was established according to the following formula: $y=0.1258 x+0.2603, R^{2}=0.9515$ ) (Figure $5 \mathrm{C})$.

Only the $\mathrm{H} 7$ subtype influenza virus strains were tested as positive in the study, whereas the sensitivity of the assay was approximately 1 or $2 \mathrm{HAU} / 50 \mu \mathrm{L}$, equal to $62 \mathrm{TCID}_{50} / 50 \mu \mathrm{L}$ and $8 \mathrm{TCID}_{50} / 50 \mu \mathrm{L}$ for $\mathrm{A} /$ Anhui/1/2013 (H7N9) and A/GD/ 17SF003/2016 (H7N9), respectively. These results indicate that this novel DAS-ELISA is specific and sensitive for the detection of the HA antigen of $\mathrm{H} 7$ subtype influenza virus (including H7N9).

\section{DISCUSSION}

Since the novel avian influenza H7N9 emerged in 2013, five epidemics have occurred in China, thus posing a threat to public health. Although the avian vaccination strategy demonstrated a sudden decrease in the number of human H7N9 infections, we still face challenges with the rapidly evolving H7 subtype influenza viruses, their increased virulence, and host range expansion (Shi et al., 2018; Zeng et al., 2018). The development of a specific and sensitive diagnostic method is essential for the management of H7N9 infections. In this study, we generated five mouse mAbs $(1 \mathrm{C} 4,2 \mathrm{~B} 3,2 \mathrm{D} 7,3 \mathrm{E} 4$, and 3E5) against the $\mathrm{HA}$ of a novel $\mathrm{H} 7$ subtype influenza (A/ Anhui/1/2013, H7N9) and developed a novel DAS-ELISA based on the optimized pairing of mAbs presenting high specificity and sensitivity in detecting the $\mathrm{HA}$ antigen of $\mathrm{H} 7$ subtype influenza virus.

Compared with polyclonal antibodies, the mAb-based immunoassays owned the advantages of stability and specificity, and they may be exploited for diagnostic applications and other research. Although several studies on mAbs against avian influenza H7N9 HA have been reported (Yang et al., 2010; Malik et al., 2016; Schmeisser et al., 2015; Tan et al., 2016; Stadlbauer et al., 2018; Vasudevan et al., 2018), 

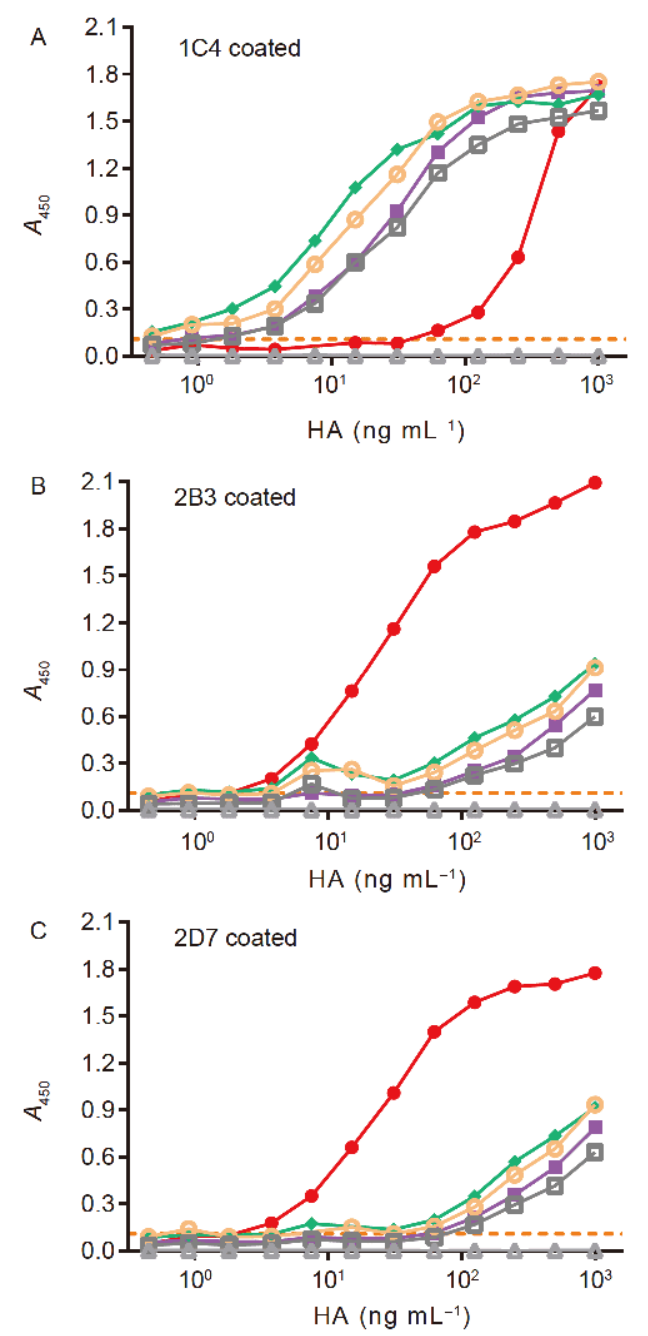
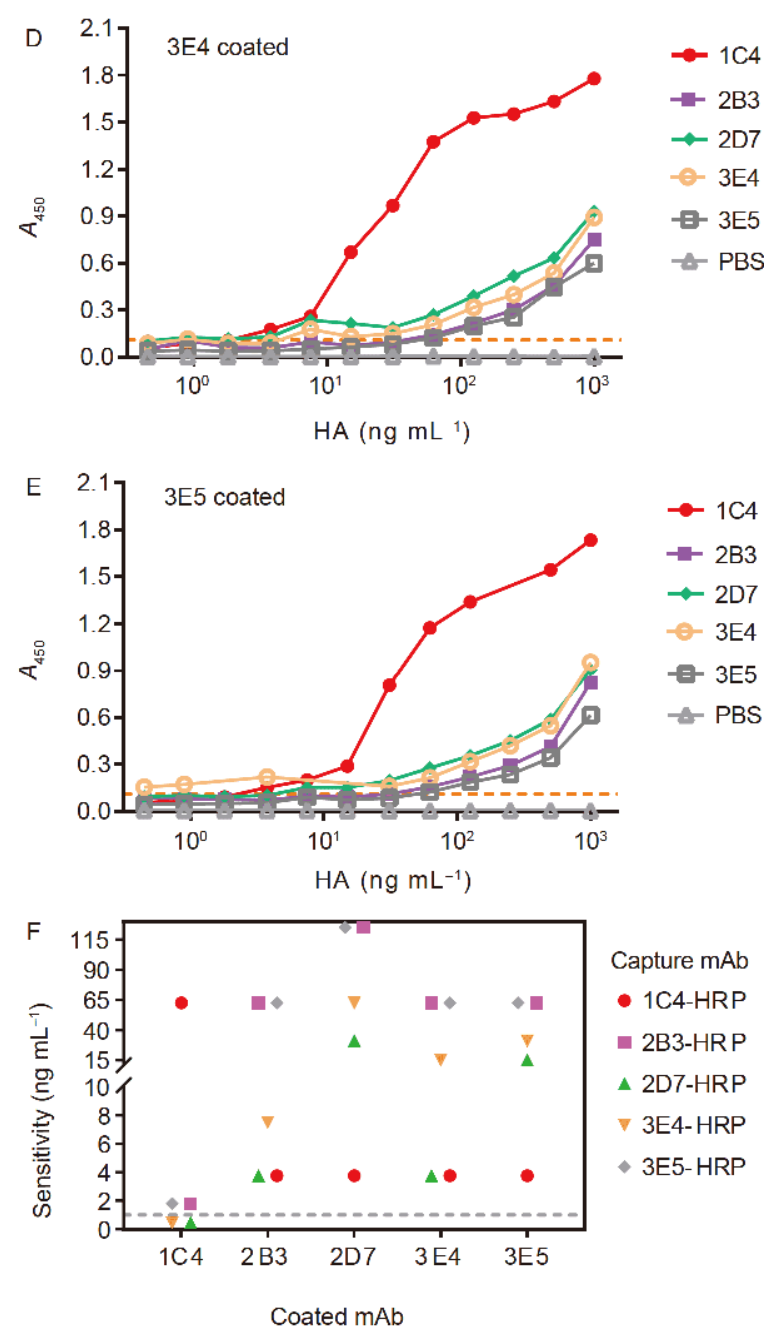

Figure 4 (Color online) Optimization of the double-antibody sandwich ELISA with paired mAbs. Five monoclonal antibodies (1C4, 2B3, 2D7, 3E4, and 3E5) with their respective HRP conjugates (HRP-1C4, HRP-2B3, HRP-2D7, HRP-3E4, and HRP-3E5) were combined in all possible arrays. The concentration of capture antibodies was $2 \mu \mathrm{g} \mathrm{mL}^{-1}$. The detection antibodies were used at a dilution of 1:10,000. A-E, Sandwich ELISA used 1C4, 2B7, 2D7, $3 \mathrm{E} 4$, and $3 \mathrm{E} 5$ as capture antibodies $\left(2 \mu \mathrm{g} \mathrm{mL}^{-1}\right)$ and paired biotinylated mAbs $(1: 10,000)$ as detector antibodies. F, Summary of detection limits for all possible combinations of mAbs used as capture and detection antibodies in sandwich ELISA.

a few focused on the neutralization effect (Malik et al., 2016, Schmeisser et al., 2015, Tan et al., 2016, Stadlbauer et al., 2018), and most of the diagnostic applications of the mAbs were derived from avian $\mathrm{H} 7$ protein prior to the novel influenza A (H7N9) virus outbreak (Vasudevan et al., 2018; Yang et al., 2010). In this study, the HA derived from novel H7 subtype influenza (A/Anhui/1/2013, H7N9) was used as immunogen for the mAb development. All five mAbs specifically reacted with the HA derived from novel $\mathrm{H} 7$ subtype influenza but not with those of other subtypes influenza viruses (H1N1, H3N2, or H5N1) in Western blot and immunofluorescence assays, indicating that these mAbs are specific to the $\mathrm{H} 7$ subtype influenza virus. In addition, our data indicate that all five mAbs are IgG1 isotype, specifically recognized as linear epitopes on the HA antigen in Western blot assay. However, only mAb $1 \mathrm{C} 4$ possessed HI activity, indicating that $1 \mathrm{C} 4$ (as the captured $\mathrm{Ab}$ in the DAS-ELISA) recognized different antigenic epitopes from 2D7 (as the detection $\mathrm{Ab}$ ) on $\mathrm{HA}$ of $\mathrm{H} 7$ subtype influenza virus. Although our data indicated that all the five $\mathrm{mAbs}$ recognized the HA aa at a range of 200-335 aa (Figure 3), a panel of Cterminal nested deletions or overlapping peptides should be generated to refine the exact epitopes of individual $\mathrm{mAb}$ in the future.

Matched capture/detection antibodies with discrete epitopes were required to develop a sensitive sandwich ELISA. To select the matched pair, we explored all arrays that combined the five mAbs with their respective conjugates. As expected, the $A$ values were low when the same antibodies were assayed as matched pairs, mainly because they recognized the same epitope of HA. We finally determined that using the coating antibody $1 \mathrm{C} 4\left(2 \mu \mathrm{g} \mathrm{mL} L^{-1}\right)$ and HRP-conjugated $\mathrm{mAb} 2 \mathrm{D} 7$ resulted in the best sensitivity and the highest absorbance. Interestingly, an $A$ value $>1.0$ was ob- 

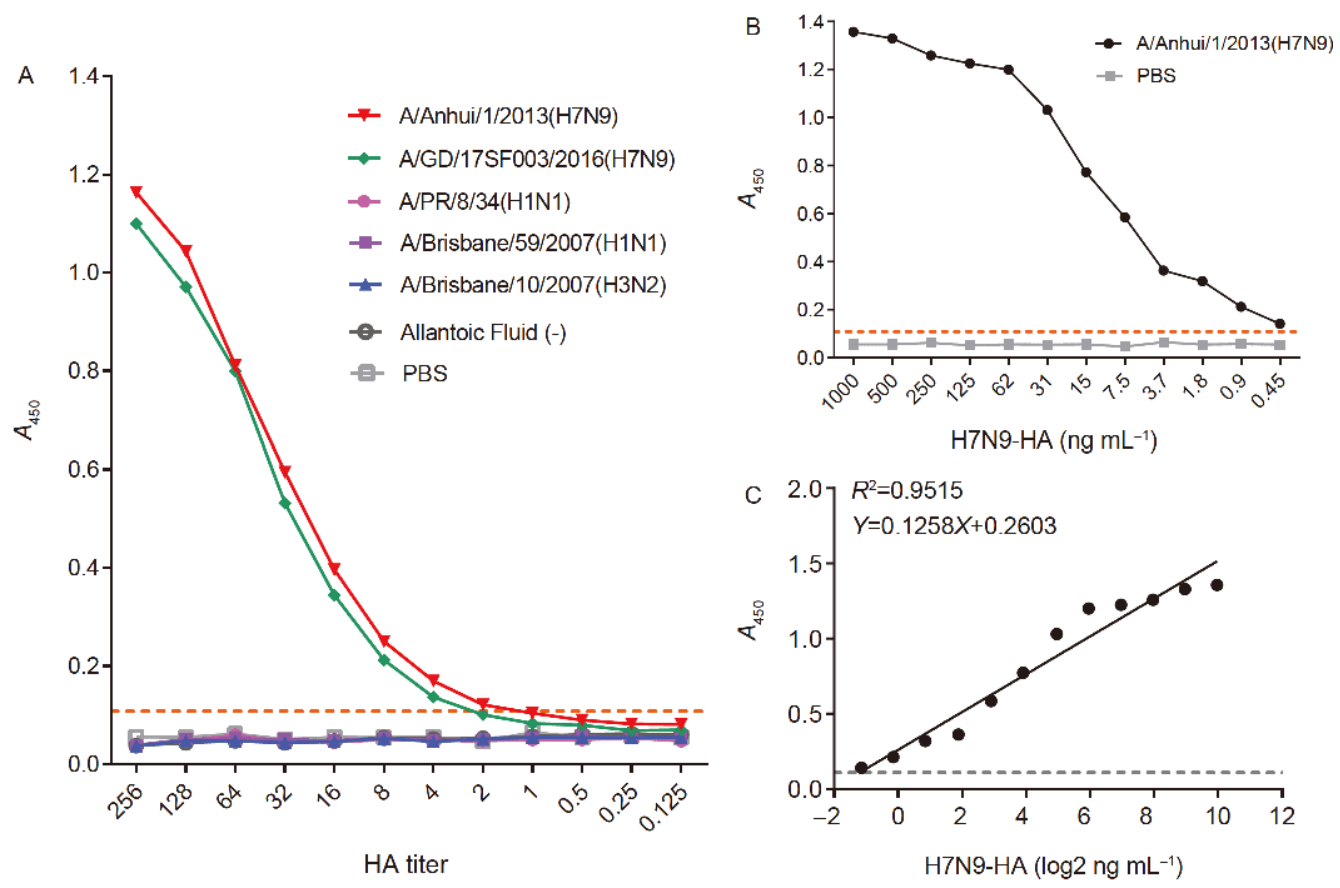

Figure 5 (Color online) Performance of sandwich ELISA with matched pair 1C4/HRP-2D7 for detecting H7N9 HA. A, The specificity and sensitivity of sandwich ELISA with 1C4 as the capture antibody $\left(2 \mu \mathrm{g} \mathrm{mL}^{-1}\right)$ and HRP-2D7 $(1: 10,000)$ as the detector antibody were analyzed with a serial dilution of influenza viruses A/Brisbane/59/2007 (H1N1), A/PR/8/1933 (H1N1), A/Brisbane/10/2007 (H3N2), A/Anhui/1/2013 (H7N9), and A/GD/17SF003/2016 (H7N9). The red dashed line indicates the cut-off value. B, The detection limit of the sandwich ELISA was analyzed using purified A/Anhui/1/2013 (H7N9) HA protein. C, The standard curve based on rHA quantification using sandwich ELISA.

served in DAS-ELISA when $1 \mathrm{C} 4$ was used as the capture antibody combined with $2 \mathrm{~B} 3,2 \mathrm{D} 7,3 \mathrm{E} 4$, or $3 \mathrm{E} 5$ as the detection antibody, indicating that the antigen binding affinity of $\mathrm{mAb} 1 \mathrm{C} 4$ was greater than that of the other mAbs. Another interesting discovery was that although $2 \mathrm{D} 7$ or $3 \mathrm{E} 4$ as the detection antibody resulted in the best sensitivity when $1 \mathrm{C} 4$ was used as the capture antibody, the $A$ value curve for $3 \mathrm{E} 4$ was slightly lower than that of $2 \mathrm{D} 7$, indicating these mAbs may recognize different epitopes.

The specificity of the DAS-ELISA in this study was also evaluated with both influenza virus representative subtypes and other clinical pathogens of the human respiratory tract. The results demonstrated that only the H7 subtype influenza virus strains tested positive in the study, whereas all other influenza subtypes and respiratory tract pathogens were tested negative with $A_{450}$ value below 0.1 or the cut-off value (data not shown). The optimized pairing of mAbs showed a good performance for the detection of HA antigens of epidemic H7N9 viruses, including the LPAI A/Anhui/1/2013 (H7N9) and the HPAI A/Guangdong/17SF003/2016 (H7N9). To our knowledge, the continuous evolution of H7N9 viruses has diversified into two lineages: the Yangtze River Delta lineage and the Pearl River Delta lineage. As A/ Anhui/1/2013 (H7N9) is a representative of the Yangtze River Delta lineage, and the A/GD/17SF003/2016 (H7N9) is a representative of highly pathogenic H7N9 variant reported in the Pearl River Delta region in Guangdong province, our data demonstrated the good performance of the established
DAS-ELISA for the detection of both lineages of H7N9 viruses in this study, indicating that the proposed detection method is applicable for the circulating H7N9 viruses. The alignments and analysis results of the HA aa sequences from five representative $\mathrm{H} 7$ strains, such as $\mathrm{A} / \mathrm{Anhui} / 1 / 2013$ (H7N9), A/Shanghai/1/2013(H7N9), A/GD/17SF003/2016 (H7N9), A/duck/Fujian/SD208/2017(H7N9), and A/duck/ Fujian/SE0195/2018(H7N2), yielded similarity ratios ranging from $95.7 \%$ to $98.6 \%$ (Figure 6). Considering the specific regions recognized by the five mAbs at 200-335 aa, the established DAS-ELISA demonstrated the potential application for further usage for the $\mathrm{H} 7$ variants detection. Additionally, although the mAb-based DAS-ELISA owned the advantages of high specificity and the unlimited supply of a standardized reagent, further studies should be conducted to confirm if this method could be applied for more variants of H7 strains, such as the recombinant H7N2 strain which appeared in a poultry in Fujian province (Shi et al., 2018).

Immunochromatographic strips with mAbs have been reported for the rapid detection of influenza viruses of H9, H7, and H5 subtypes (Peng et al., 2008; Kang et al., 2014; Yeo et al., 2017; Nguyen et al., 2017; Iwatsuki-Horimoto et al., 2018). In a europium nanoparticle-based rapid diagnostic method with $\mathrm{mAbs}$ against avian influenza $\mathrm{H} 7$, the detection limits of the fluorescent immunochromatographic strip test employing novel mAbs were $31 \mathrm{ng} \mathrm{mL}^{-1}$ for H7N9 rHA1 protein and $40 \mathrm{HAU} \mathrm{mL} \mathrm{m}^{-1}(2 \mathrm{HAU} / 50 \mu \mathrm{L})$ for $\mathrm{H} 7$ subtype virus (Yeo et al., 2017). In an early study for the development 
A

\begin{tabular}{|c|c|c|c|c|c|c|c|}
\hline & \multicolumn{7}{|c|}{ Percent Identity } \\
\hline & & 1 & 2 & 3 & 4 & 5 & \\
\hline \multirow{6}{*}{ 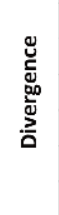 } & 1 & & 98.4 & 97.3 & 96.6 & 96.6 & 1 \\
\hline & 2 & 1.6 & & 96.1 & 95.4 & 95.7 & 2 \\
\hline & 3 & 2.7 & 4.0 & & 98.6 & 98.2 & 3 \\
\hline & 4 & 3.5 & \begin{tabular}{|l}
4.8 \\
\end{tabular} & 1.4 & & 98.6 & 4 \\
\hline & 5 & 3.5 & 4.4 & 1.8 & 1.4 & & 5 \\
\hline & & 1 & 2 & 3 & 4 & 5 & \\
\hline
\end{tabular}

B

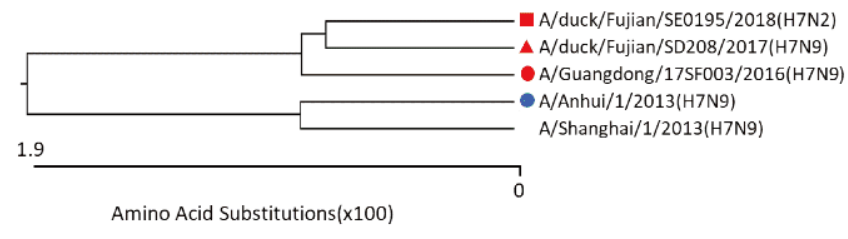

C

A/Anhui/1/2013(H7N9) A/Shanghai/1/2013(H7N9) A/Guangdong/17SF003/2016(H7N9) A/duck/Fujian/SD208/2017(H7N9) A/duck/Fujian/SE0195/2018(H7N2)

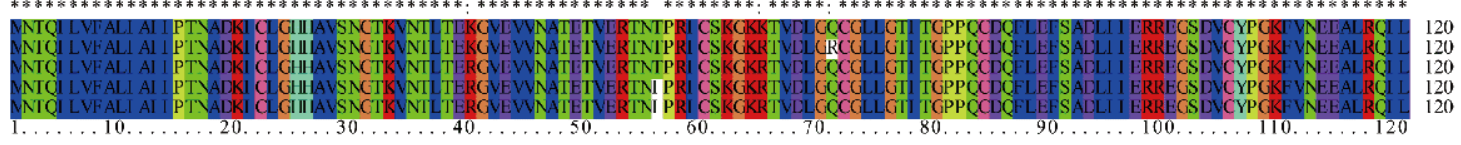
N/duck/Fujian/SD208/2017(H7N9) Nduck/Fujian/SE0195/2018(H7N2) N/Anhui/1/2013(H7N9) N/Anhui/1/2013(H7N9)

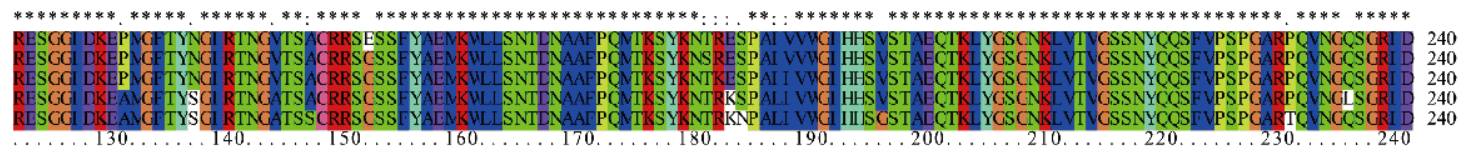

A/duck/Fujlan/sD2018/2017(117N9) N/duck/Fujian/SE0195/2018(H7N2) A/Guangdong/178F003/2016(H7N9) A/Anhui/1/2013(117N9)

N/duck/Fujian/SD208/2017(H7N9) N/duck/Fujian/SE0195/2018(H7N2) NGuangdong/17SF003/2016(H7N9) N/Anhui/1/2013(H7N9) A/Shanghai/1/2013(117N9)

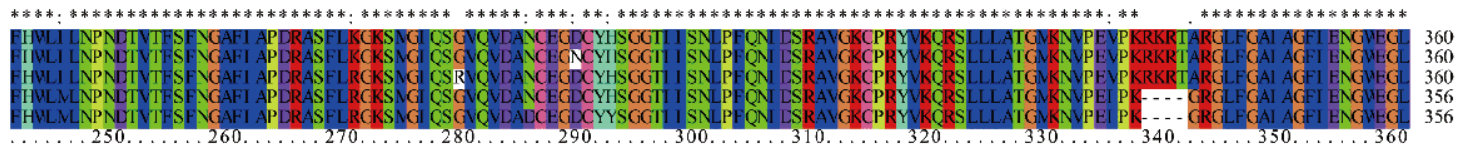

Aduck/Fujian/SD208/2017(H7N9) A/duck/liujlan/SE:0195/2018(117N2) A/cuangdong/175r:003/2016(117N9) N/Anhui/1/2013(H7N9) A/Shanghai/1/2013(117N9)

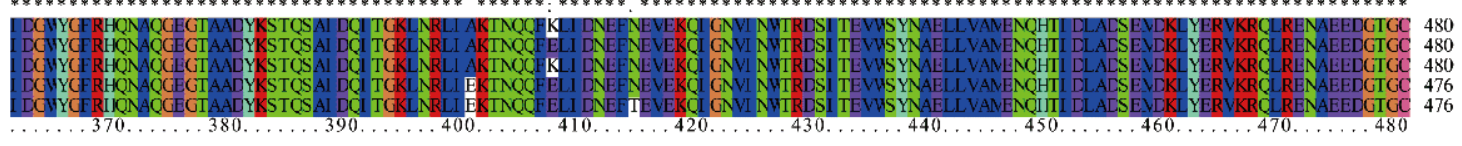

N/ducl/Fujian/SD208/2017(H7N9) A/duck//ujian/SE:0195/2018(117 N2) NGuangdong/75ro03/2016 A/Shhungi/1/2013(H7Na)

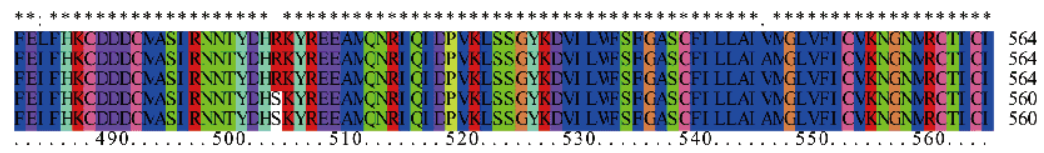

Figure 6 HA protein amino-acid sequence alignments and phylogenetic analysis of representative H7 subtype strains. A, Alignment results for amino-acid (aa) sequence of A/Anhui/1/2013(H7N9), A/Shanghai/1/2013(H7N9), A/GD/17SF003/2016 (H7N9), A/duck/Fujian/SD208/2017(H7N9), and A/duck/Fujian/SE0195/2018(H7N2), with the GISAID accession numbers EPI138739, EPI138737, and EPI919606 and GenBank accession numbers MH209515.1 and MH209523.1, respectively. B, Phylogenetic tree for aa sequences of representative H7 subtype strains by MEGA 5.0.5 software. C, Multiple sequence alignments for aa sequences of representative H7 subtype strains by CLUSTAL X (2.0) software.

of a rapid diagnostic test for the novel avian influenza A (H7N9) virus with anti-HA mAb specifically targeting $\mathrm{H} 7$ in an immunochromatographic assay system (Kang et al., 2014), the limit of detection was $10^{3} \mathrm{TCID}_{50}$ for $\mathrm{A} /$ Anhui/1/ 2013 (H7N9), comparable with the $C_{\mathrm{t}}$ value of 29 in realtime RT-PCR. In a recent study on the development of an influenza rapid diagnostic kit specific for the $\mathrm{H} 7$ subtype (Iwatsuki-Horimoto et al., 2018), the author compared the H7 kit with that of the commercially available influenza rapid diagnostic kit ImunoAce Flu (TAUNS Laboratories, Inc., Shizuoka, Japan), which can detect both influenza A and $\mathrm{B}$ viruses. The ImunoAce Flu kit gave positive results with $10^{2}-10^{4.7} \mathrm{TCID}_{50}$ of the tested $\mathrm{H} 7$ viruses, whereas the $\mathrm{H} 7$ kit required $10^{5.7}-10^{7.3} \mathrm{TCID}_{50}$ of the tested $\mathrm{H} 7$ viruses. In our study, the detection limits were 1 and $2 \mathrm{HAU} / 50 \mu \mathrm{L}$, which are equal to $10^{3}$ and $10^{2} \mathrm{TCID}_{50}$, for $\mathrm{A} / \mathrm{Anhhui} / 1 / 2013$ (H7N9) and A/Guangdong/17SF003/2016 (H7N9), respectively. Overall, the DAS-ELISA used in this study demonstrated a comparable or superior performance and potential application for detecting $\mathrm{H} 7$ antigen and subtype influenza virus to the commercial kits for antigen detection.

The anti-HA mAb-based DAS-ELISA may also provide an alternative assay for influenza vaccine potency; it requires strain-specific mAbs and optimized pairing of antibodies. The WHO released two recommendations for influenza A (H7N9) candidate vaccine viruses since 2013. Initially, the organization recommended using the $\mathrm{A} /$ Anhui/1/2013 (H7N9) or A/Shanghai/2/2013 (H7N9) for a candidate vaccine virus in 2013 and then updated their report to A/ Guangdong/17SF003/2016 (H7N9) or A/Hunan/02650/2016 (H7N9) in 2017. A capture ELISA with mAbs against H7 HA was recently developed to quantify the HA of inactivated influenza vaccine A/Shanghai/2/2013 (H7N9) (Vasudevan et al., 2018). The five mAbs produced in our study and the matched pair 1C4/HRP-2D7 sandwich ELISA may be further developed for the characterization and quantification of HA antigen in developing vaccines against H7N9.

In summary, we developed five mAbs against influenza A (H7N9) HA protein and a novel DAS-ELISA for detecting HA antigen and influenza A (H7N9) using the optimized pair 
of mAbs (1C4/2D7). Our study may provide a valuable approach to diagnose $\mathrm{H} 7$ subtype influenza infection and to quantify the HA for vaccine development against epidemic H7N9. However, our study presented several limitations, and further investigations should also be conducted. For example, to evaluate the performance of the proposed DASELISA, additional clinical samples from influenza-infected patients or poultry should be tested for diagnostic applications, and the concentrations of the paired mAbs should also be further optimized in the DAS-ELISA or in another improved platform.

\section{MATERIALS AND METHODS}

\section{Influenza viruses}

The influenza viruses used in this study included A/Anhui/1/ 2013 (H7N9), A/Guangdong/17SF003/2016 (H7N9), A/ Brisbane/10/2007 (H3N2), A/Brisbane/59/2007 (H1N1), and A/Puerto Rico/8/34 (H1N1). All these viruses are reassortant candidate vaccine viruses and possess $\mathrm{HA}$ and neuraminidase genes derived from the above viruses. The above viruses were produced in allantoic cavities of 9-day-old embryonated chicken eggs at $33^{\circ} \mathrm{C}$ for $48 \mathrm{~h}$, and the HA titers were detected with $0.5 \%$ turkey red blood cells (RBCs).

\section{Clinical samples containing other viruses}

Nose and throat swab samples from patients with acute respiratory tract infections were kept in our laboratory and used in this study. All the clinical samples had been detected as positive for specific respiratory tract pathogens, including human coronaviruses 229E, OC43, NL63, and HKU1; RSV, PIVs, rhinovirus, and AdV, using molecular assays as per previous reports (Liu et al., 2019; Yu et al., 2012).

\section{HA-expressing plasmids}

The HA-expressing plasmids contained the full-length HA from A/Anhui/1/2013 (H7N9), A/Anhui/1/2005 (H5N1), A/ Brisbane/10/2007 (H3N2), and A/Brisbane/59/2007 (H1N1), with the GenBank accession numbers EPI439507, DQ371928.1, EU199366.1, and CY058487.1, respectively. The transient transfection experiments were performed with the DNA transfection reagent of X-treme GENE HP (Roche Diagnostics) following the manufacturer's instructions.

\section{Mice immunization and $\mathbf{m A b}$ production}

The rHA of A/Anhui/1/2013 (H7N9) expressed in a baculovirus-insect sf9 cell system (Sino Biological, Inc.) was used as the immunogen. Three 4-week-old female BALB/c mice were first immunized with $30 \mu \mathrm{g}$ HA in complete
Freund's adjuvant (Sigma) subcutaneously, boosted with rHA in incomplete Freund's adjuvant (Sigma) 14 days later, and finally boosted again with the immunogen without adjuvants. A final immunization of rHA was administered 3 days prior to fusion. The mAbs were produced by inoculating the selected hybridoma into BALB/c mice as previously described (Köhler and Milstein, 2005). Isotyping was performed with a Pierce isotyping kit (Thermo). The ascetic fluid was collected, and the mAbs were purified by ammonium sulfate precipitation. The $\mathrm{mAb}$ concentration was measured by the BCA Protein Assay Reagent (Thermo). To identify the heavy and light chains, $0.5 \mu \mathrm{g}$ produced $\mathrm{mAb}$ was subjected to SDS-PAGE. The binding affinity of serum, hybridoma supernatants, or ascetic fluid was determined by indirect ELISA as described previously (Wang et al., 2016). The average $A_{450}$ values for normal controls were calculated, and the cut-off values were determined as the average of $2.1 \times$ normal controls. The animal experiments were conducted with the China Guidance for the Care and Use of Laboratory Animals of China CDC.

\section{Western blot assay}

For Western blot analysis, 293FT cells were cultured on sixwell plates overnight until $80 \%$ confluence and transfected with $2 \mu \mathrm{g}$ empty vector of pVRC8301 or pVRC8301 expressing HA of A/Anhui/1/2013 (H7N9) HA, A/Anhui/1/ 2005 (H5N1), A/Brisbane/10/2007 (H3N2), or A/Brisbane/ 59/2007 (H1N1). After 48 h, PBS was used to wash the cells, which were then collected and lysed. Cell lysates were assessed by Western blotting as described previously (Wang et al., 2016).

\section{Indirect immunofluorescence assay}

For the immunofluorescence assays, MDCK cells were grown in 96-well plates overnight until $80 \%$ confluence and transfected with $0.1 \mu \mathrm{g}$ plasmid pVRC8301 empty vector or pVRC8301 expressing HA of A/Anhui/1/2013 (H7N9) HA, A/Anhui/1/2005 (H5N1), A/Brisbane/10/2007 (H3N2), or A/Brisbane/59/2007 (H1N1). After $24 \mathrm{~h}$, the transfected cells were fixed with $4 \%$ paraformaldehyde. Then, $30 \mathrm{~min}$ afterward, the cells were incubated with $\mathrm{mAb}$ diluted to 1:100, followed by incubation with the FITC-labeled antimouse IgG antibody 1:100 (Sigma-Aldrich). The cells were examined using a laser confocal microscope.

\section{Epitope mapping of the mAbs}

To evaluate the specific regions recognized by the mAbs, a series of C-terminal truncation HA fragments of A/Anhui/1/ 2013(H7N9) was synthesized and cloned into the pVRC8301 expression vector between the EcoR V and $B g l$ II restriction 
sites, and all sequences were confirmed by restricted enzyme digestion and DNA sequencing. The fragments included the full-length $\mathrm{A} /$ Anhui/1/2013(H7N9) HA, aa 1-335 of HA, and aa 1-200 of HA, which were labeled F1, F2, and F3, respectively. The HA of highly pathogenic avian influenza $\mathrm{A} / \mathrm{GD} / 17 \mathrm{SF} 003 / 2016$ (H7N9) was cloned into the pVRC8301 expression vector as positive control, which was named as H7. The plasmid pVRC8301 empty vector was used as a mock control. All these constructs were expressed by transient transfection and were analyzed by Western blotting as described above. The cells were incubated with $\mathrm{mAb}$ diluted to 1:500, and polyclonal mouse serum collected from $\mathrm{BALB} / \mathrm{c}$ immunized with the same recombinant HA protein of A/Anhui/1/2013 (H7N9) was diluted to 1:200 as the positive control.

\section{HI assay}

The $\mathrm{HI}$ activity for each $\mathrm{mAb}$ was assayed using $0.5 \%$ turkey RBCs in 96-well plates (V-bottom). Briefly, $4 \mathrm{HAU} / 25 \mu \mathrm{L}$ influenza virus was mixed with the same volume of $\mathrm{mAb}$ in a V-bottom plate. After $1 \mathrm{~h}, 1 \% \mathrm{RBCs}$ in $50 \mu \mathrm{L}$ was added, and the plate was incubated for $30 \mathrm{~min}$. The HI titer was calculated as the highest dilution of each mAb that totally inhibited the hemagglutination of tested viruses.

\section{Selection of matched capture/detection antibodies}

To select the matched pair capture/detection antibodies, 96well plates were coated with $2 \mu \mathrm{g} \mathrm{mL}^{-1}$ purified $\mathrm{mAb}(1 \mathrm{C} 4$, $2 \mathrm{~B} 3,2 \mathrm{D} 7,3 \mathrm{E} 4$, and 3E5) in carbonate buffer for $16 \mathrm{~h}$ at $4^{\circ} \mathrm{C}$. After washing, the ELISA plates were blocked with $2 \%$ BSA for $1 \mathrm{~h}$ at $37^{\circ} \mathrm{C}$. After washing, serially diluted rHA proteins were added. After incubating for $1 \mathrm{~h}$, the plates were washed, and $\mathrm{mAbs}$ conjugated to HRP (HRP-1C4, HRP-2B3, HRP2D7, HRP-3E4, and HRP-3E5) and diluted to 1:10,000 were added. After $1 \mathrm{~h}$, the plates were washed and visualized with TMB substrate and stopped with an equal volume of $2 \mathrm{~mol} \mathrm{~L}^{-1} \mathrm{H}_{2} \mathrm{SO}_{4}$. An ELISA plate reader was used to measure the $A_{450}$ absorbance value.

\section{DAS-ELISA for $\mathrm{H} 7$ antigen detection}

To perform DAS-ELISA, the 96-well plates were coated with $\mathrm{mAb} 1 \mathrm{C} 4\left(2 \mu \mathrm{g} \mathrm{mL}^{-1}\right)$ for $16 \mathrm{~h}$ at $4^{\circ} \mathrm{C}$. Then, the plates were washed and blocked with BSA for $1 \mathrm{~h}$. After washing with PBST, serially diluted antigens or inactivated influenza viruses were added and then incubated for $1 \mathrm{~h}$ at $37^{\circ} \mathrm{C}$. After washing, the paired HRP-2D7 $(1: 10,000)$ was added. After $1 \mathrm{~h}$, the TMB substrate was added, and an equal volume of $2 \mathrm{~mol} \mathrm{~L}^{-1} \mathrm{H}_{2} \mathrm{SO}_{4}$ was used to stop the reaction. An ELISA plate reader was used to measure the $A_{450}$ absorbance value.

\section{Statistical analysis}

The data analysis was performed by GraphPad Prism v.7 (GraphPad Software Inc.). The results of the ELISA are indicated as the mean \pm SD of three replicates. Significance was considered as $P<0.05$. The concentration standard curve of HA protein was calculated by the linear regression analysis method.

\section{Sequence alignments and phylogenetic analysis}

The aa sequences of A/Anhui/1/2013(H7N9), A/Shanghai/1/ 2013(H7N9), A/GD/17SF003/2016 (H7N9), A/duck/Fujian/ SD208/2017(H7N9), and A/duck/Fujian/SE0195/2018 (H7N2) were assigned with the Global Initiative on Sharing All Influenza Data accession numbers EPI138739, EPI138737, and EPI919606 and GenBank accession numbers MH209515.1 and MH209523.1, respectively. The sequences were aligned using the CLUSTAL X2.0 algorithm (Larkin et al., 2007) implemented on the MegAlign of DNASTAR program package (DNASTAR Inc., Madison, USA). The phylogenetic analyses were carried out using MEGA version 5.0.5 software (Tamura et al., 2011).

Compliance and ethics The author(s) declare that they have no conflict of interest.

Acknowledgements We thank Dr. Gary Nabel (Vaccine Research Center, NIAID, NIH) for providing $p$ VRC8301 plasmid. This work was financially supported by the National Key Research and Development Program of China (2016YFD0500300 to W.T., 2016YFC1200200 to B.H. and J.Z.), and the National Natural Science Funds for Young Scholar of China (No.31200127 to B.H.). The funders had no role in study design, data collection and analysis, decision to publish, or preparation of the manuscript. We thank Dr. Jonathan Audet for his critical discussion.

\section{References}

Gao, R., Cao, B., Hu, Y., Feng, Z., Wang, D., Hu, W., Chen, J., Jie, Z., Qiu, $\mathrm{H}$., $\mathrm{Xu}, \mathrm{K}$., et al. (2013). Human infection with a novel avian-origin influenza A (H7N9) virus. N Engl J Med 368, 1888-1897.

Iwatsuki-Horimoto, K., Shi, J., Wang, X., Sakai-Tagawa, Y., Ito, M., Murakami, K., da Silva Lopes, T.J., Nakaishi, K., Yamayoshi, S., Watabe, S., et al. (2018). Development of an influenza rapid diagnostic kit specific for the H7 subtype. Front Microbiol 9, 1346.

Kang, K., Chen, L., Zhao, X., Qin, C., Zhan, Z., Wang, J., Li, W., Dzakah, E.E., Huang, W., Shu, Y., et al. (2014). Development of rapid immunochromatographic test for hemagglutinin antigen of $\mathrm{H7}$ subtype in patients infected with novel avian influenza A (H7N9) virus. PLoS ONE 9, e92306.

Köhler G., and Milstein C. (2015). Continuous cultures of fused cells secreting antibody of predefined specificity, 1975. J Immunol 174, 24532455.

Koski, R.R., and Klepser, M.E. (2017). A systematic review of rapid diagnostic tests for influenza: considerations for the community pharmacist. J Am Pharm Assoc 57, 13-19.

Larkin, M.A., Blackshields, G., Brown, N.P., Chenna, R., McGettigan, P. A., McWilliam, H., Valentin, F., Wallace, I.M., Wilm, A., Lopez, R., et al. (2007). Clustal W and Clustal X version 2.0. Bioinformatics 23, 2947-2948. 
Li, J., Kou, Y., Yu, X., Sun, Y., Zhou, Y., Pu, X., Jin, T., Pan, J., and Gao, G. F. (2014). Human co-infection with avian and seasonal influenza viruses, China. Emerg Infect Dis 20, 1953-1955.

Liu, G.S., Niu, P.H., Zhao, S.C., Lu, R.J., and Tan, W.J. (2019). Detection of six common human paramyxoviruses in patients with acute febrile respiratory symptoms using a novel multiplex real-time RT-PCR assay. J Med Virol 91, 564-569.

Malik, A., Mallajosyula, V., Mishra, N.N., Arukha, A.P., Varadarajan, R., and Gupta, S.K. (2016). Generation and characterisation of monoclonal antibodies specific to avian influenza H7N9 haemagglutinin protein. Ind J Med Microbiol 34, 489-494.

Nguyen, L.T., Nakaishi, K., Motojima, K., Ohkawara, A., Minato, E., Maruyama, J., Hiono, T., Matsuno, K., Okamatsu, M., Kimura, T., et al. (2017). Rapid and broad detection of H5 hemagglutinin by an immunochromatographic kit using novel monoclonal antibody against highly pathogenic avian influenza virus belonging to the genetic clade 2.3.4.4. PLoS ONE 12, e0182228.

Peng, F., Wang, Z., Zhang, S., Wu, R., Hu, S., Li, Z., Wang, X., and Bi, D. (2008). Development of an immunochromatographic strip for rapid detection of H9 subtype avian influenza viruses. Clin Vaccine Immunol $15,569-574$.

Qi, W., Jia, W., Liu, D., Li, J., Bi, Y., Xie, S., Li, B., Hu, T., Du, Y., Xing, L., et al. (2018). Emergence and Adaptation of a Novel Highly Pathogenic H7N9 Influenza Virus in Birds and Humans from a 2013 Human-Infecting Low-Pathogenic Ancestor. J Virol 92.

Quan, C., Shi, W., Yang, Y., Yang, Y., Liu, X., Xu, W., Li, H., Li, J., Wang, Q., Tong, Z., et al. (2018). New threats from H7N9 influenza virus: spread and evolution of high- and low-pathogenicity variants with high genomic diversity in wave five. J Virol 92, e00301-18.

Sala, G., Cordioli, P., Moreno-Martin, A., Tollis, M., Brocchi, E., Piccirillo, A., and Lavazza, A. (2003). ELISA test for the detection of influenza H7 antibodies in avian sera. Avian Dis 47, 1057-1059.

Schmeisser, F., Vasudevan, A., Verma, S., Wang, W., Alvarado, E., Weiss, C., Atukorale, V., Meseda, C., and Weir, J.P. (2015). Antibodies to antigenic site $\mathrm{A}$ of influenza $\mathrm{H} 7$ hemagglutinin provide protection against H7N9 challenge. PLoS ONE 10, e0117108.

Shah, K., and Maghsoudlou, P. (2016). Enzyme-linked immunosorbent assay (ELISA): the basics. British J Hospital Med 77, C98-C101.

Stadlbauer, D., Amanat, F., Strohmeier, S., Nachbagauer, R., and Krammer, F. (2018). Cross-reactive mouse monoclonal antibodies raised against the hemagglutinin of A/Shanghai/1/2013 (H7N9) protect against novel $\mathrm{H} 7$ virus isolates in the mouse model. Emerg Microb Infect 7, 1-12.

Shi, J., Deng, G., Kong, H., Gu, C., Ma, S., Yin, X., Zeng, X., Cui, P., Chen, Y., Yang, H., et al. (2017). H7N9 virulent mutants detected in chickens in China pose an increased threat to humans. Cell Res 27, 1409-1421.

Shi, J., Deng, G., Ma, S., Zeng, X., Yin, X., Li, M., Zhang, B., Cui, P.,
Chen, Y., Yang, H., et al. (2018). Rapid evolution of H7N9 highly pathogenic viruses that emerged in China in 2017. Cell Host Microbe 24, 558-568.e7.

Tamura, K., Peterson, D., Peterson, N., Stecher, G., Nei, M., and Kumar, S. (2011). MEGA5: molecular evolutionary genetics analysis using maximum likelihood, evolutionary distance, and maximum parsimony methods. Mol Biol Evol 28, 2731-2739.

Tan, G.S., Leon, P.E., Albrecht, R.A., Margine, I., Hirsh, A., Bahl, J., and Krammer, F. (2016). Broadly-reactive neutralizing and non-neutralizing antibodies directed against the $\mathrm{H} 7$ influenza virus hemagglutinin reveal divergent mechanisms of protection. PLoS Pathog 12, e1005578.

Vasudevan, A., Woerner, A., Schmeisser, F., Verma, S., Williams, O., and Weir, J.P. (2018). Potency determination of inactivated H7 influenza vaccines using monoclonal antibody-based ELISA and biolayer interferometry assays. Influenza Other Respir Viruses 12, 250-258.

Velumani, S., Du, Q., Fenner, B.J., Prabakaran, M., Wee, L.C., Nuo, L.Y., and Kwang, J. (2008). Development of an antigen-capture ELISA for detection of $\mathrm{H} 7$ subtype avian influenza from experimentally infected chickens. J Virol Meth 147, 219-225.

Wang, D., Yang, L., Zhu, W., Zhang, Y., Zou, S., Bo, H., Gao, R., Dong, J., Huang, W., Guo, J., et al. (2016). Two outbreak sources of influenza A (H7N9) viruses have been established in China. J Virol 90, 5561-5573.

Wang, W., Wang, H., Deng, Y., Song, T., Lan, J., Wu, G., Ke, C., and Tan, W. (2016). Characterization of anti-MERS-CoV antibodies against various recombinant structural antigens of MERS-CoV in an imported case in China. Emerg Microbe Infect 5, 1-12.

WHO Global Influenza Surveillance Network. (2011). Manual for the laboratory diagnosis and virological surveillance of influenza.

Yang, L., Zhu, W., Li, X., Chen, M., Wu, J., Yu, P., Qi, S., Huang, Y., Shi, W., Dong, J., et al. (2017). Genesis and spread of newly emerged highly pathogenic H7N9 avian viruses in mainland China. J Virol 91.

Yang, M., Clavijo, A., Graham, J., Pasick, J., Neufeld, J., and Berhane, Y. (2010). Evaluation of diagnostic applications of monoclonal antibodies against avian influenza H7 viruses. Clin Vaccine Immunol 17, 13981406.

Yeo, S.J., Bao, D.T., Seo, G.E., Bui, C.T., Kim, D.T.H., Anh, N.T.V., Tien, T.T.T., Linh, N.T.P., Sohn, H.J., Chong, C.K., et al. (2017). Improvement of a rapid diagnostic application of monoclonal antibodies against avian influenza H7 subtype virus using Europium nanoparticles. Sci Rep 7, 7933.

Yu, X., Lu, R., Wang, Z., Zhu, N., Wang, W., Julian, D., Chris, B., Lu, J., Lv, J., and Tan, W. (2012). Etiology and clinical characterization of respiratory virus infections in adult patients attending an emergency department in Beijing. PLoS ONE 7, e32174.

Zeng, X., Tian, G., Shi, J., Deng, G., Li, C., and Chen, H. (2018). Vaccination of poultry successfully eliminated human infection with H7N9 virus in China. Sci China Life Sci 61, 1465-1473. 